\title{
Criação de representações usando e-lixo para homenagear mulheres da Computação
}

\author{
Matheus Mattos de Almeida Cruz ${ }^{1}$, Sílvia Amélia Bim¹, Ligia Cristina Battezzati², \\ Mateus Santos $^{1}$, Rita C. G. Berardi ${ }^{1}$, Valissa Paiva ${ }^{1}$ \\ ${ }^{1}$ Departamento Acadêmico de Informática - UTFPR Curitiba - PR - Brasil \\ ${ }^{2}$ Instituto Federal do Paraná - Curitiba - PR - Brasil \\ matheuscruzealunos.utfpr.edu.br, sabimeutfpr.edu.br, \\ ligia.battezzati@ifpr.edu.br, ritaberardi@utfpr.edu.br, \\ \{matteus.santostb, valissa.paiva\}@gmail.com
}

\begin{abstract}
The reduction in the number of women working in the Computing area is a worldwide concern. Actions of various kinds carried out by various initiatives seek to reverse the scenario by disseminating different aspects of computing to motivate girls and women to choose the area as a profession. In this article, the experience of a workshop held in the discipline of Art in the first year of high school in a public institution is shared. The workshop's proposal was to take the gender discussion in Computing through a creative activity with electronic waste.
\end{abstract}

Resumo. A redução do número de mulheres atuando na área de Computação é uma preocupação mundial. Ações de diversas naturezas realizadas por inúmeras iniciativas buscam reverter o cenário divulgando diferentes aspectos da Computação para motivar meninas e mulheres a escolherem a área como profissão. Neste artigo, é compartilhada a experiência de uma oficina realizada na disciplina de Arte do primeiro ano do ensino médio do Instituto Federal do Paraná. A proposta da oficina foi levar a discussão de gênero em Computação através de uma atividade criativa com lixo eletrônico.

\section{Introdução}

Diversas ações vêm sendo realizadas nos últimos anos com o objetivo de aumentar a representatividade de mulheres na área de Computação pois, observa-se no cenário brasileiro que desde 2009 há uma redução do número de mulheres que ingressam e que concluem cursos de ensino superior nesta área no Brasil [Nunes 2015]. O Programa Meninas Digitais da Sociedade Brasileira de Computação completa em 2020 dez anos de atuação, com mais de cem projetos realizando ações em todas as regiões do Brasil para reverter o cenário e aumentar o número de mulheres trabalhando na Computação. As ações são muito diversificadas, incluindo oficinas sobre temas diversos da Computação, palestras e visitas técnicas [Maciel et al. 2018].

Este artigo traz o relato de uma oficina realizada com uma turma de primeiro ano do Curso Técnico em Informática Integrado ao Ensino Médio do Instituto Federal do Paraná (IFPR). A oficina foi incluída no programa da disciplina de Artes I buscando ilustrar como atividades de Computação podem ser integradas ao currículo comum. Fazendo uso de lixo eletrônico cada grupo de estudante deveria criar uma instalação 
artística em homenagem a uma mulher que tenha contribuído para a área de Computação. Desta forma, os temas de sustentabilidade e de equidade de gênero foram abordados e articulados.

A proposta da oficina também está articulada com um dos princípios para orientar a educação escolar apresentado nos parâmetros curriculares nacionais dentro dos temas transversais [Brasil 2000]: igualdade de direitos em que se discutem as desigualdades socioeconômicas e de gênero. Além disto, a realização da oficina possibilita um diálogo transversal com alguns Objetivos de Desenvolvimento Sustentável (ODS) ${ }^{1}$ : ODS 4 - Educação de qualidade, ODS 5 - Igualdade de gênero, ODS 10 - Redução das desigualdades e ODS 12 - Consumo e produção responsáveis.

Este artigo está organizado da seguinte forma: na seção 2 - são apresentados alguns trabalhos relacionados, em seguida, na seção 3 a metodologia utilizada nas atividades da oficina é apresentada. A seção 4 apresenta as instalações criadas e as mulheres homenageadas. Por fim, são feitas considerações sobre a experiência relatada neste artigo.

\section{Trabalhos Relacionados}

Um grande número de ações para despertar o interesse de mulheres para a Computação usa como estratégia, a apresentação e a prática de conceitos da área, como por exemplo [Maciel et al. 2012] que através de atividades desplugadas aborda conceitos de Interação Humano-Computador (IHC) bem como [Berardi et al. 2018] faz uso de caixas de ovos para o ensino de vetores.

O tema do lixo eletrônico também é abordado em trabalhos realizados com estudantes do ensino médio. O trabalho de [Fraguas et al. 2019] propõe uma sequência de 13 aulas sobre o lixo eletrônico para serem realizadas com estudantes do ensino médio. Sendo a aula 10 sobre palavras cruzadas e histórias em quadrinhos sobre lixo eletrônico, a aula 11 sobre produção de cartazes informativos com reportagens e a aula 13 sobre elaboração de banner sobre o lixo eletrônico que poderiam ser realizadas no contexto das aulas de Artes.

Por outro lado, os trabalhos que articulam os temas Computação, mulheres e lixo eletrônico ainda são incipientes. Um trabalho pioneiro é o de [Castilho et al. 2019] que leva uma escultura de Ada Lovelace, criada com resíduos eletrônicos, para escolas públicas de Porto Alegre. A partir da apresentação da escultura e da realização de oficinas com conhecimentos técnicos e de práticas das Artes Visuais integradas são discutidos temas como gênero, obsolescência programada e descarte adequado de lixo eletrônico de forma interdisciplinar. A oficina Montando e Conhecendo, descrita em [Castilho et al. 2019] serviu de inspiração para a oficina descrita neste artigo.

\section{Metodologia}

A oficina foi realizada em três sextas-feiras consecutivas no final de maio e início de junho de 2019 no horário das aulas de Arte I. A disciplina tinha dois horários de aulas de 50 minutos cada com um intervalo de 15 minutos entre elas. A equipe responsável pela oficina era composta de uma docente universitária e três estudantes do curso de

\footnotetext{
${ }^{1}$ https://nacoesunidas.org/pos2015/agenda2030/
} 
Sistemas de Informação. Todas as atividades da oficina foram acompanhadas pela professora de Arte I, docente do ensino básico, técnico e tecnológico (EBTT). No segundo dia de oficina houve a colaboração de uma voluntária, estudante de Ciências Sociais para a separação das peças do lixo eletrônico.

No primeiro dia foram realizadas atividades para apresentar os temas principais da oficina: mulheres na Computação e lixo eletrônico. O roteiro das atividades foi: (1) Apresentação sobre o Programa Meninas Digitais da SBC e sobre o projeto parceiro Emíli@s - Armação em bits ${ }^{2}$ e equipe responsável pela atividade (25min); (2) Apresentação sobre Mulheres na Computação (25min); (3) Intervalo; (4) Apresentação do projeto Enigma (10min), [Castilho et al. 2019]; (5) Exibição do vídeo sobre o espetáculo Ada.Ada.Ada (2min); (6) Apresentação de exemplos do que pode ser feito com o lixo eletrônico e arte (10min); (7) Jogos sobre Mulheres na Computação (25min) - Jogo da Memória, Damas Digitais (inspirado no jogo Damas Chinesas) e Computasseia ${ }^{3}$.

No segundo dia foram realizadas três atividades: (a) formação dos grupos de estudantes; (b) escolha da mulher da computação que seria homenageada e; (c) início da criação da representação usando lixo eletrônico. A equipe responsável pela oficina levou diversos itens considerados lixo eletrônico (e.g. mouse, teclado, dvd, aparelho de som) para que cada grupo de estudantes escolhesse os itens que fossem necessários para a criação da representação em homenagem a uma mulher da Computação. Alguns itens precisaram ser desmontados em peças menores. A atividade de desmontar e manusear as ferramentas foi feita pela equipe responsável, conforme demanda dos grupos. No terceiro e último dia os grupos concluíram a montagem das representações e fizeram apresentações para a turma, explicando sobre a mulher homenageada, sobre o processo de criação da representação e sobre os significados da representação.

\section{Resultados}

A turma onde a oficina foi realizada tinha 28 estudantes, sendo 12 do gênero feminino e 16 do gênero masculino. Foram formados seis grupos. Embora tenha sido sugerido que os grupos fossem diversificados, na característica gênero, dois grupos foram formados apenas por meninos e um grupo foi formado apenas por meninas.

O grupo 1, formado por duas meninas e dois meninos, escolheu homenagear Hedy Lamarr (Figura 1a). O grupo 2, formado também por duas meninas e dois meninos, homenageou Hipátia de Alexandria (Figura 1b). O grupo 3, formado por cinco meninos criou uma representação para homenagear Margaret Hamilton (Figura 1c). O grupo 4, formado por quatro meninas também escolheu homenagear Margaret Hamilton (Figura 1d). O grupo 5, formado por quatro meninas e dois meninos homenageou Katie Bouman (Figura 1e). E por fim, o grupo 6, formado apenas por cinco meninos também homenageou Hedy Lamarr (Figura 1f). No último dia da oficina o estudante do grupo 3 que estava responsável pela representação de Margaret Hamilton não foi à aula. Os quatro estudantes presentes criaram uma nova representação diferente da primeira por falta dos itens de lixo eletrônico necessários.

\footnotetext{
${ }^{2}$ http://emilias.dainf.ct.utfpr.edu.br/

${ }^{3}$ http://gameinclass.ic.ufmt.br/computassy/index.html
} 


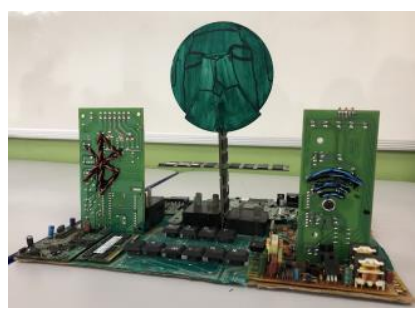

(a) G1: Hedy Lamarr

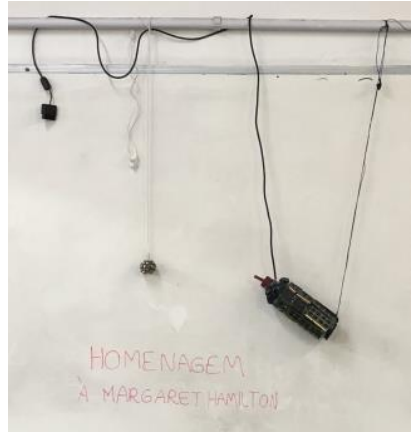

(d) G4: Magaret Hamilton

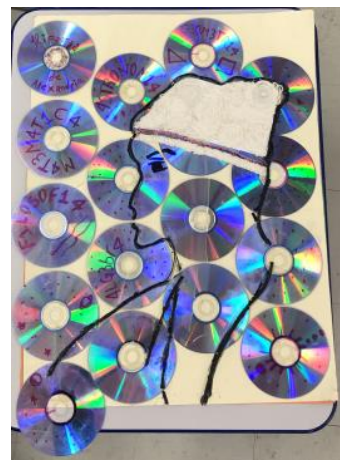

(b) G2: Hipatia

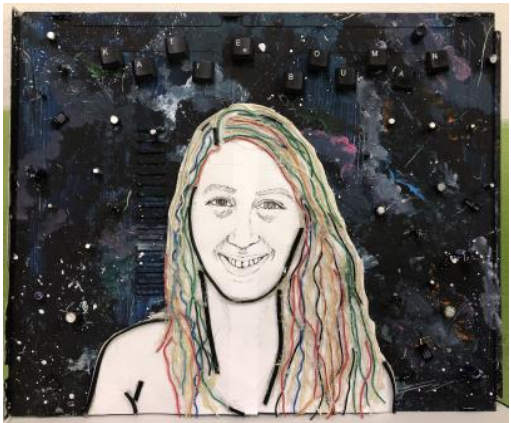

(e) G5: Katie Bouman

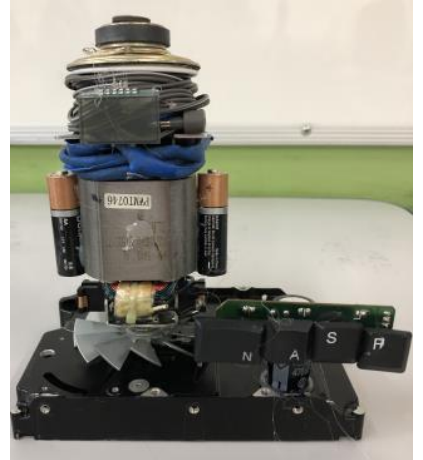

(c) G3: Margaret Hamilton

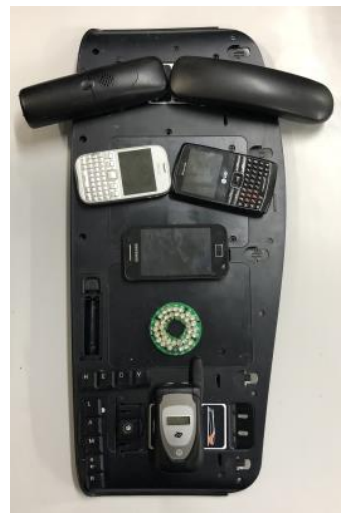

(f) G6: Hedy Lamarr

Figura 1. Representações das mulheres da computação

\section{Considerações finais}

A realização da oficina no contexto da disciplina de Arte I se deu primeiramente pela disponibilidade e interesse da professora responsável pela disciplina. Com esta dinâmica, foi possível explorar a interdisciplinaridade, desenvolvimento e identificação cultural, multiculturalidade e o papel de elo de ligação da Arte com outras disciplinas. [Barbosa 2018].

Foi possível trabalhar, dentro da ementa da disciplina de Arte I, com alguns tópicos de artes visuais, como o papel da arte na humanidade e o desenvolvimento e compreensão das manifestações artísticas em seus diferentes contextos. O contato dos estudantes com o lixo eletrônico foi relevante, principalmente, no sentido de ressignificar esses objetos e torná-los parte de criações artísticas com conceitos e significados relacionados às profissionais homenageadas.

O intervalo entre as duas aulas de cada dia de oficina era um momento mais informal de interação com a turma. Além disto, estudantes de outras turmas eventualmente entravam na sala na hora do intervalo e se interessavam em saber o que estava acontecendo. Uma das estudantes que visitou a sala demonstrou interesse na oficina e no curso de Computação.

Segundo [Ribeiro 2019], o ensino de Computação auxilia no desenvolvimento de todas as competências gerais da Base Nacional Comum Curricular. Na oficina 
realizada várias competências foram trabalhadas, conforme descrição das atividades e dos resulta- dos. Pode-se destacar a competência Compreensão do Mundo tanto na perspectiva dos impactos ambientais do uso da tecnologia quanto nas contribuições das mulheres para o desenvolvimento da Computação. As atividades em grupo, na escolha da mulher a ser homenageada e na construção da representação trabalharam a competência de Empatia e Cooperação. De maneira transversal, também foi possível trabalhar com as competências de Argumentação e Comunicação (na justificativa da escolha das mulheres e da intenção na criação da representação), Pensamento Crítico e Criativo e Repertório Cultural. E a longo prazo acredita-se que a experiência possa levar ao desenvolvimento da competência Trabalho e Projeto de Vida pois, meninas e meninos podem se inspirar nas histórias de vida das mulheres homenageadas e escolher a Computação como profissão.

Além disto, a oficina pode ser considerada um exemplo de atividade que contempla a perspectiva de Tecnologia e Sociedade dentro do eixo Cultura Digital, um dos três eixos da Computação.

\section{Referências}

Barbosa, A. M. (2018). Inquietações e mudanças no ensino da arte. Cortez Editora.

Berardi, R. C., Bim, S. A., Macuch, R., and Dal Forno, L. F. (2018). Experiência de uso de caixas de ovos no apoio ao ensino de vetores e matrizes. In Anais do XXVI Workshop sobre Educação em Computação. SBC.

Brasil, P. C. N. (2000). Parâmetros curriculares nacionais: A apresentação dos temas transversais e ética.

Castilho, N., Rapkiewicz, C., and Fogazzi, S. (2019). Uma escultura de Ada Lovelace como recurso educativo para trabalhar gênero na computação. In Anais do XIII Women in Information Technology, p. 129-133. SBC.

Fraguas, T. et al. (2019). Lixo eletrônico no contexto da educação ambiental: um estudo de caso junto a professores do ensino m' médio. Dissertação de mestrado, Universidade Tecnológica Federal do Paraná.

Maciel, C., Bim, S. A., and Boscarioli, C. (2012). A fantástica fábrica de chocolate: levando o sabor de IHC para meninas do ensino fundamental. In Companion Proceedings of the 11th Brazilian Symposium on Human Factors in Computing Systems, p. 27-28. Sociedade Brasileira de Computação.

Maciel, C., Bim, S. A., e Figueiredo, K. da S. (2018). "Digital girls program: disseminating computer science to girls in Brazil." In Proceedings of the 1st International Workshop on Gender Equality in Software Engineering, p. 29-32.

Nunes, D. (2015). Educação superior em computação, estatísticas 2015. Sociedade Brasileira de Computação - SBC. Disponível em: http://www. sbc. org. br/documentosdasbc/summary/133-estatisticas/1074-educacaosuperior-em-Computação-estatisticas-2015. Acesso em 15/05/2020, 6.

Ribeirto, L. (2019). Ensino de computação na Educação Básica - as diretrizes da SBC. Computação Brasil - Revista da Sociedade Brasileira de Computação, Porto Alegre, n.41, p. 6-9. 